\title{
THE DEMOGRAPHIC GAP IN CONFERENCE COMMITTEES
}

\author{
Omar Salman, Susan Gauch, Mohammed Alqahatani and Mohammed Ibrahim \\ University of Arkansas, Fayetteville AR 72701, USA
}

\begin{abstract}
In this study, we explore the demographic composition of conference program committees (PCs) in Computer Science by modeling the demographic profile of a researcher considering four distinct demographic features. In addition to the widely used gender and race, we also consider institution rank and geolocation to model demographic attributes of a researcher. We use this multi-dimensional profile to explore the demographic gap in the scientific community by analyzing the top two ACM conferences (ranked by impact factor). We tracked these conferences over a decade to analyze the makeup of their program committees to look for progress in closing the gap over time. Our analysis shows there is a slight improvement in terms of gender; however, there has been no diversity increase in ethnicity or institution rank. The results show that the percentage of PC members from developing countries is generally below $6 \%$. We believe that this work highlights the importance of considering demographic features to achieve fair representation in scientific conferences in order to open the door for the development of new fair and diverse academic expertise recommendations.
\end{abstract}

\section{KEYWORDS}

Demographic Bias, Researcher Modeling, Academic Conferences

\section{INTRODUCTION}

Scientific conferences are venues in which people with a common scientific interest meet to share their work and knowledge. They play an obvious role in the success of scholars since they provide the environment that fosters social and professional networking. Individuals attend conferences to present their new research to get feedback from their peers, learn about new advancements in their field of interest, and establish social connections with other scientists and professionals (McCarthy et al., 2004). In a published survey by The Scientist (Aiken, 2006) in which over 1,000 scholars participated, two-thirds of the participants indicated that attending a conference had changed the course of their research, 52\% stated they learned new things that saved time and money for their work, and $60 \%$ reported that their connections in conferences led to new collaboration. Given this evidence that attending a conference is important for career advancement and the professional success of an individual researcher, it is crucial that these opportunities are available to researchers from diverse backgrounds. As the gatekeepers for paper acceptance, this translates into a need for program committees (PC) to themselves have diverse representation. Nevertheless, it can be argued that many conferences adopted double blind review; however, several studies show that 25-40\% of the time, reviewers can identify authors (Baggs et al., 2008; Justice et al., 1998) which might lead to bias. Our work highlights trends in the demographic makeup of two Computer Science conference program committees over the past decade, illustrating the need for further progress. Fortunately, one of the conferences that we studied, SIGCHI (Conference on Human Factors in Computing Systems), has reported that its PC will become more demographically diverse in 2020 (Bjørn and Zhao, 2019).

Many studies show that women and minorities are underrepresented in academic conferences, negatively impacting their professional and academic careers. For example, a study by the Nature Magazine shows that women from underrepresented groups are less likely to be selected to present at a conference but more likely to be chosen to present a poster instead (Ford et al., 2019). Gender bias in the peer review process has been investigated in (Lerback and Hanson, 2009; Murray et al., 2019) in which the results show that female authors are less likely to have their paper selected. Ethnicity is also a potential source of bias in academia. For instance, it has been reported that only 6 out of 8500 attendees at the NIPS conference in 2016 were 
black (Snow, 2018). Furthermore, the US National Science Foundation report (National Science Foundation, 2017) states that minority ethnic and racial groups are underrepresented in graduate programs and this negatively impacts their social and professional advancement.

Geolocation and nationality are other sources of bias within the scientific community. The literature provides evidence for the lack of geolocation diversity and the dominance of a small number of countries, most of which are developed, in the publication and the peer review process (Burgess and Shaw, (2010); Cummings and Hoebink, 2017; Goyanes, 2020; König, 2019). A report published by Publons (Publons, 2018) states that the US dominated the peer review process, providing $32.9 \%$ of the reviewers, although the US provided only $25.4 \%$ of the publications between 2013 and 2017. It also shows that 11 countries reviewed more than two third of all articles published by the Web of Science for the same period. The study also indicates that editors usually selected reviewers from developed countries or from their own region which is one reason that could account for the lower rate of reviewers from the emerging countries. They study also showed that an Asian scholar affiliated with US-based university has a higher chance to be selected to a PC compared with scholars who are affiliated with Asian-based university despite the increasing number of publications from developing countries. However, when researchers who are geographically isolated and from different ethnicity collaborate with other researchers from majority groups, their work receives more citations and it gets published in a high impact journal (Freeman and Huang, 2015). This illustrates how important it is to involve researchers from a wide range of locations in the peer review process of major conferences by including them on the conference program committees.

University rankings can affect the selection of individuals to join an academic team (Bornmann and Daniel, 2005) and the acceptance of papers to publish (Tomkins et al., 2017). Thus, we chose to include this demographic parameter in our research to determine if this factor plays a role in program committee membership. Research communities may find this bias easily explainable; top researchers work at top universities. However, we assert that good research is more widely distributed across many institutions and university rank alone is not sufficient to determine the quality of a submitted paper. Qualified scholars from lower-ranked universities are also likely to reap the most benefits from the networking opportunities afforded by serving on program committees and presenting at top conferences.

In this paper, we investigate the composition of conference program committees using a multi-dimensional researcher profile that we introduce here. In contrast to previous studies that discuss modeling the demographic profile for a researcher by considering one demographic attribute or two (such as gender or race), we present a represent a researcher's demographic profile via four different parameters: gender, ethnicity, geolocation, and university rank. We use these profiles to study demographic trends in Computer Science conference committees, and we have constructed a dataset of 706 researchers, members of the program committees (PC) for two high impact factor ACM-sponsored conferences: SIGCHI (Conference on Human Factors in Computing Systems) and SIGMOD (Symposium on Principles of Database Systems). For each conference, we profiled the PC members from three years that span a decade, i.e., 2007, 2012, and 2017, and analyzed their composition over this time period with respect to gender, race, geolocation (i.e., whether it is a developed or developing country), and university rank to get initial data on diversity trends. Our result shows that investigating this number of attributes provides a broader view on the need to have a demographic diversity on the composition of conference committees. This diversity should not be limited to one attribute (such as gender), but scientific community attention is required to consider and further study the impact of other parameters on the development of scholar career.

The rest of this paper discusses the dataset and how we build the demographic for profile for each researcher. The dataset presented in this paper has been made publicly available at (http://www.csce.uark.edu/ oasalman/dataset/) for researchers who are interested in studying the demographic bias in scientific communities. 


\section{DATASET AND METHODS}

\subsection{Method}

The Association for Computing Machinery (ACM) is an international non-profit scientific association with more than 100,000 members as of 2019. It is considered the oldest and largest computing society in the world, and it has 37 Special Interest Groups (SIGs) that reflect different computing disciplines. These groups are the leading representatives for their fields and sponsor annual conferences and workshops including highly competitive conferences in which to participate and publish (ACM, 2020). We choose to study the composition of the program committees (PCs) for two of the top ACM-SIG conferences in terms of impact factor (Aminer, 2020): SIGCHI (Conference on Human Factors in Computing Systems) and SIGMOD (Symposium on Principles of Database Systems). We tracked these conferences over a decade and collected the data for three different years. We build a tool that collects the program committee member names for each conference and downloads the corresponding homepages or resumes for each member. To create a highly accurate dataset, we manually extracted the four demographic attributes that are gender, ethnicity, geolocation, and the university rank.

\subsection{Dataset}

The dataset consists of 706 member profiles. In this section, we will analyze the demographic trend for each attribute. We report on percentage increases and decreases over the past decade to determine whether any progress has been made to eliminate any existing demographic gap.

\subsubsection{Gender}

Women make up $27 \%$ of computer science professionals in the US (National Science Foundation, 2020). Female participation in SIGCHI's PC is quite strong, $40.85 \%$ in 2017, exceeding this general participation rate, although still lagging the actual representation of females in the population. In contrast, the SIGMOD PC is only $17.7 \%$ female which leaves women underrepresented even with respect to their participation in computer science. Both conferences improved the participation of females on their PCs from 2007 to 2012 as in Table 1 and Table 2, which is encouraging. Nevertheless, both saw a decrease in the participation of female members in 2017, indicating that more work needs to be done to solidify past gains.

Table 1. Gender distribution for SIGCHI PC for the years 2007, 2012, and 2017

\begin{tabular}{ccccccccc}
\hline \multicolumn{2}{c}{ SIGCHI 2007 } & \multicolumn{3}{c}{ SIGCHI 2012 } & \multicolumn{2}{c}{ SIGCHI 2017 } \\
\hline Gender & Count & $\%$ & Count & $\%$ & \% Increase & Count & $\%$ & $\%$ Increase \\
& & & & & & & & \\
Female & 37 & 41.57 & 37 & 45.68 & 9.89 & 87 & 40.85 & -10.57 \\
Male & 52 & 58.43 & 44 & 54.32 & -7.03 & 126 & 59.15 & 8.89 \\
Total & 89 & 100 & 81 & 100 & & 213 & 100 & \\
\hline
\end{tabular}

Table 2. Gender distribution for SIGMOD PC for the years 2007, 2012, and 2017

\begin{tabular}{ccccccccc}
\hline \multicolumn{2}{c}{ SIGMOD 2007 } & \multicolumn{3}{c}{ SIGMOD 2012 } & \multicolumn{3}{c}{ SIGMOD 2017 } \\
\hline Gender & Count & $\%$ & Count & $\%$ & $\%$ Increase & Count & $\%$ & $\%$ Increase \\
& & & & & & & & \\
Female & 9 & 9.78 & 24 & 23.76 & 142.94 & 23 & 17.70 & -25.51 \\
Male & 83 & 90.22 & 77 & 76.24 & -15.50 & 107 & 82.30 & 7.95 \\
Total & 92 & 100 & 101 & 100 & & 130 & 100 & \\
\hline
\end{tabular}




\subsubsection{Ethnicity}

Table 3 and Table 4 present our findings regarding the race and ethnicity composition of the program committees, a major source of bias in previous studies (Snow, 2018; National Science Foundation, 2017) and only $13 \%$ of computer science professionals are members of underrepresented minorities (National Science Foundation, 2020). To model ethnicities, we have used the same races defined by United States Census Bureau in (Census US, 2016) with considering Hispanic as a race and not ethnicity. Our results show that whites dominate the majority of the PC members while other races are underrepresented in both conferences.

Table 3. Ethnicity distribution for SIGCHI PC for the years 2007, 2012, and 2017

\begin{tabular}{ccccccccc}
\hline \multicolumn{2}{c}{ SIGCHI 2007} & \multicolumn{3}{c}{ SIGCHI 2012 } & \multicolumn{3}{c}{ SIGCHI 2017 } \\
\hline Ethnicity & Count & $\%$ & Count & $\%$ & \% Increase & Count & $\%$ & $\%$ Increase \\
& & & & & & & & \\
White & 78 & 87.64 & 70 & 86.42 & -1.39 & 167 & 78.40 & -9.28 \\
Asian & 8 & 8.99 & 10 & 12.35 & 37.37 & 39 & 18.31 & 48.26 \\
Other Races & 3 & 3.37 & 1 & 1.23 & -63.50 & 7 & 3.29 & 167.48 \\
Total & 89 & 100 & 81 & 100 & & 213 & 100 & \\
\hline
\end{tabular}

Table 4. Ethnicity distribution for SIGMOD PC for the years 2007, 2012, and 2017

\begin{tabular}{ccccccccc}
\hline \multicolumn{2}{c}{ SIGMOD 2007 } & \multicolumn{3}{c}{ SIGMOD 2012 } & \multicolumn{3}{c}{ SIGMOD 2017 } \\
\hline Ethnicity & Count & $\%$ & Count & $\%$ & $\%$ Increase & Count & $\%$ & $\%$ Increase \\
& & & & & & & & \\
White & 53 & 57.61 & 67 & 66.34 & 15.15 & 86 & 66.15 & -0.29 \\
Asian & 39 & 42.39 & 33 & 32.67 & -22.93 & 42 & 32.31 & -1.1 \\
Other Races & 0 & 0 & 1 & 0.99 & 0 & 2 & 1.54 & 55.56 \\
Total & 92 & 100 & 101 & 100 & & 130 & 100 & \\
\hline
\end{tabular}

\subsubsection{Geolocation}

Geolocation is another source of potential bias during the peer review process as (Publons, 2018) so we investigated the geodiversity of the conference program committee members. We modeled the geolocation distribution of SIGMOD and SIGCHI program committee using the United Nation Classification (United Nations, 2019) of developed and developing countries. The results in Table 5 show that the SIGCHI PC has very few members from developing countries (just 5.63\% in 2017), although that is an improvement over the past which had no members from a developing country in 2007. The SIGMOD PC statistics in Table 6 show a higher rate of participation from developing countries, $19.57 \%$ in 2007 , however the trend since then is fluctuating, showing a decrease in 2012 and an increase in 2017.

Table 5. Geolocation distribution for SIGCHI PC for the years 2007, 2012, and 2017

\begin{tabular}{|c|c|c|c|c|c|c|c|c|}
\hline \multicolumn{3}{|c|}{ SIGCHI 2007} & \multicolumn{3}{|c|}{ SIGCHI 2012} & \multicolumn{3}{|c|}{ SIGCHI 2017} \\
\hline Geolocation & Count & $\%$ & Count & $\%$ & $\%$ Increase & Count & $\%$ & $\%$ Increase \\
\hline Developed & 88 & 98.88 & 78 & 96.30 & -2.61 & 201 & 94.37 & -2.00 \\
\hline Developing & 1 & 1.12 & 1 & 1.23 & 9.82 & 12 & 5.63 & 357.72 \\
\hline Cannot Be & 0 & - & 2 & 2.47 & - & 0 & 0 & - \\
\hline Determined & & & & & & & & \\
\hline Total & 89 & 100 & 81 & 100 & & 213 & 100 & \\
\hline
\end{tabular}


Table 6. Geolocation distribution for SIGMOD PC for the years 2007, 2012, and 2017

\begin{tabular}{ccccccccc}
\hline \multicolumn{2}{c}{ SIGMOD 2007 } & \multicolumn{3}{c}{ SIGMOD 2012 } & \multicolumn{3}{c}{ SIGMOD 2017 } \\
\hline Geolocation & Count & $\%$ & Count & $\%$ & \% Increase & Count & $\%$ & $\%$ Increase \\
& & & & & & & & \\
Developed & 74 & 80.43 & 89 & 88.12 & 9.56 & 108 & 83.08 & -5.72 \\
Developing & 18 & 19.57 & 12 & 11.88 & -39.29 & 22 & 16.92 & 42.42 \\
Total & 92 & 100 & 101 & 100 & & 130 & 100 & \\
\hline
\end{tabular}

\subsubsection{University Rank}

Finally, university ranking can affect the selection of an individual in joining an academic team (Bornmann and Daniel, 2005). Table 7 and Table 8 show that in 2017 roughly $70 \%$ of the PC committee members for both conferences are from universities ranked higher than 200 in the world by The Times Higher Education World University Rankings (Times Higher Education, 2019). The rankings cover more than 1400 universities (and there are many more that are unranked), so the majority of the PC members come from the top 10-15\% of all universities. The trend shows little variation over the decade studied, although there is evidence of a slight decrease in participation of scholars at lower-ranked universities for both conferences. We can also notice that the total number of program committee members studied has slightly decreased due to the increased in program committee members from industry whom we excluded from our dataset.

Table 7. University rank distribution for SIGCHI PC for the years 2007, 2012, and 2017

\begin{tabular}{ccccccccc}
\hline \multicolumn{2}{c}{ SIGCHI 2007 } & \multicolumn{3}{c}{ SIGCHI 2012 } & \multicolumn{3}{c}{ SIGCHI 2017 } \\
\hline $\begin{array}{c}\text { University } \\
\text { Rank }\end{array}$ & Count & $\%$ & Count & $\%$ & $\%$ Increase & Count & $\%$ & $\%$ Increase \\
$<200$ & 36 & 67.92 & 32 & 68.09 & 0.25 & 144 & 67.61 & -0.70 \\
$>=200$ & 17 & 32.08 & 15 & 31.91 & -0.53 & 69 & 32.39 & 1.50 \\
Total & 53 & 100 & 47 & 100 & & 213 & 100 & \\
\hline
\end{tabular}

Table 8. University rank distribution for SIGMOD PC for the years 2007, 2012, and 2017

\begin{tabular}{ccccccccc}
\hline \multicolumn{2}{c}{ SIGMOD 2007 } & \multicolumn{3}{c}{ SIGMOD 2012 } & \multicolumn{2}{c}{ SIGMOD 2017 } \\
\hline $\begin{array}{c}\text { University } \\
\text { Rank }\end{array}$ & Count & $\%$ & Count & $\%$ & $\%$ Increase & Count & $\%$ & $\%$ Increase \\
$<200$ & 50 & 66.67 & 45 & 70.31 & 5.46 & 91 & 70 & -0.44 \\
$>=200$ & 25 & 33.33 & 19 & 29.69 & -10.92 & 39 & 30 & 1.04 \\
Total & 75 & 100 & 64 & 100 & & 130 & 100 & \\
\hline
\end{tabular}

\section{DISCUSSION AND CONCLUSION}

In this paper, we tried to highlight the issue of the demographic gap in scientific conferences. We selected two of the top ACM conferences as a case study to explore the opportunities for academics from diverse backgrounds to be part of prestigious conference program committees. In contrast to many studies that investigated the same issue that focuses on one parameter at a time, our demographic profile consists of four different attributes: gender, ethnicity, geolocation, and university rank.

The evidence of a gender gap in these two conferences was not surprising and they confirm previous studies (Lerback and Hanson, 2017; Murray et al., 2019) that highlight the gender gap in the scientific communities, especially in the STEM field. SIGCHI has a much lower demographic gap than SIGMOD, reaching a high of $45 \%$ female in 2012 versus $24 \%$ female for SIGMOD, also in 2012. Unfortunately, both conferences show an increase in the participation of women in their PCs in 2012 followed by a drop in 2017, showing how difficult it is to solidify past gains.

Race discrimination in the scientific community has been given a considerable amount of attention (Snow, 2018) and scholars from underrepresented minorities have been shown to have few chances to serve 
on editorial boards or give talks in scientific conferences. Our results reconfirm this problem. In the ACM conferences we studied, the percentage of ethnic minorities (i.e., Black or Hispanic) is less than $4 \%$ in the best case. At one extreme, the SIGMOD PC contained no black or Hispanic scholars in 2007 and one from those races in 2012. This highlights the need for conference program chairs to make their team more diverse by increasing the opportunities for the scholar from those races to participate and serve in these communities.

Our results show that the geolocation of the scholar's affiliated university plays a key role in selecting researchers to serve in these two conference's PCs. Both conferences show low participation from developing countries; however, SIGMOD shows a better inclusion percentage for the developing countries $(12 \%-20 \%)$ compared to $5.63 \%$ in the best cases of SIGCHI PC.

Finally, our data shows that most PC members are drawn from high ranking universities. Although this is a potential source of bias, it has received relatively little attention in the scientific community. Our results show that roughly $70 \%$ of the PC members are drawn from top ranked institutions and the ratios was quite consistent for both conferences over time. This can lead to a closed society in which opportunities are not widely shared and also to echo chambers in which the same voices are always heard.

Overall, our dataset provides strong motivation that there is a need to broaden the participation of researchers from a wide range of demographic groups. Our dataset can be extended to study the impact of other demographic attributes such as re-searcher's impact and career stage and further evaluated by scholar recommendation and scientific team formation algorithms. As a future work, we plan to add to use this dataset in testing algorithms for diverse expert recommendation systems. We hope that our work is the first step towards tools that will allow identifying the demo-graphic parameters that are considered major sources of bias and ensure that minorities are well represented and have the same advantages that the majorities have.

\section{REFERENCES}

ACM. About the ACM Organization. [Online]. Available at: https://www.acm.org/about-acm/about-the-acm-organization [Accessed 4 Sep. 2020].

Aiken, J. (2006). What's the Value of Conferences?. [Online]. Available at: http://www.the-scientist.com/uncategorized/whats-the-value-of-conferences-47563 [Accessed 4 Sep. 2020].

Aminer. Conference Rank: Computer Science. [Online]. Available at: https://www.aminer.cn/ranks/conf [Accessed 4 Sep. 2020].

Baggs, J.G., Broome, M.E., Dougherty, M.C., Freda, M.C. and Kearney, M.H., 2008. Blinding in peer review: the preferences of reviewers for nursing journals. Journal of advanced nursing, Vol. 64, No. 2, pp.131-138.

Bjørn, P., Zhao, S., 2019. Diversity of the Program Committee for CHI 2020 [Online]. Available at: https://chi2020.acm.org/blog/diversity-of-the-program-committee-for-chi-2020/ [Accessed 4 Sep. 2020].

Bornmann, L. and Daniel, H. D., 2005. Selection of research fellowship recipients by committee peer review. Reliability, fairness and predictive validity of Board of Trustees' decisions. Scientometrics, Vol. 63, No. 2, pp.297-320.

Burgess, T.F. and Shaw, N.E., 2010. Editorial board membership of management and business journals: A social network analysis study of the Financial Times 40. British Journal of Management, Vol. 21, No. 3, pp.627-648.

Census US (2016). 2015 National Content Test Study Plan - Race \& Ethnicity. [Online]. Available at: https://www2.census.gov/programs-surveys/decennial/2020/program-management/final-analysis-reports/2020-report2015NCT-Race-Ethnicity-Study-Plan.pdf [Accessed 4 Sep. 2020].

Cummings, S. and Hoebink, P., 2017. Representation of academics from developing countries as authors and editorial board members in scientific journals: does this matter to the field of development studies?. The European Journal of Development Research, Vol. 29, No. 2, pp.369-383.

Ford, H. L., Brick, C., Azmitia, M., Blaufuss, K. and Dekens, P., 2019. Women from some under-represented minorities are given too few talks at world's largest Earth-science conference, Nature, Vol. 576, pp. 23-35.

Freeman, R.B. and Huang, W., 2015. Collaborating with people like me: Ethnic coauthorship within the United States. Journal of Labor Economics, Vol. 33, No. S1, pp.S289-S318.

Goyanes, M., 2020. Editorial boards in communication sciences journals: Plurality or standardization?. International Communication Gazette, Vol. 82, No. 4, pp.342-364.

Justice, A.C., Cho, M.K., Winker, M.A., Berlin, J.A., Rennie, D. and Peer Investigators, 1998. Does masking author identity improve peer review quality?: A randomized controlled trial. Jama, Vol. 280, No. 3, pp.240-242.

König, C.J., 2019. How much is research in the top journals of industrial/organizational psychology dominated by authors from the US?. Scientometrics, Vol. 120, No. 3, pp.1147-1161. 
Lerback, J. and Hanson, B., 2017. Journals invite too few women to referee. Nature, Vol. 541, pp.455-457.

McCarthy, J.F., McDonald, D.W., Soroczak, S., Nguyen, D.H. and Rashid, A.M., 2004. Augmenting the social space of an academic conference. In Proceedings of the 2004 ACM conference on Computer supported cooperative work (pp. 39-48).

Murray, D., Siler, K., Larivière, V., Chan, W.M., Collings, A.M., Raymond, J. and Sugimoto, C.R., 2019. Gender and international diversity improves equity in peer review. BioRxiv, p.400515.

National Science Foundation (2017). Women, Minorities, and Persons with Disabilities in Science and Engineering. [Online]. Available at: https://www.nsf.gov/statistics/2017/nsf17310/ [Accessed 4 Sep. 2020].

National Science Foundation (2020). The State of U.S. Science and Engineering 2020. [Online]. Available at: https://ncses.nsf.gov/pubs/nsb20201/u-s-s-e-workforce [Accessed 4 Sep. 2020].

Publons (2018). Global State Of Peer Review. [Online]. Available at: https://publons.com/static/Publons-Global-StateOf-Peer-Review-2018.pdf [Accessed 4 Sep. 2020].

Snow, J. (2018). We're in a diversity crisis. [Online]. Available at: https://www.technologyreview.com/2018/02/14/145462/were-in-a-diversity-crisis-black-in-ais-founder-on-whatspoisoning-the-algorithms-in-our/ [Accessed 4 Sep. 2020].

Times Higher Education, World University Rankings 2019 by subject: computer science. [Online]. Available at: https://www.timeshighereducation.com/world-university-rankings/2019/subject-ranking/computerscience\#!/page/0/length/25/sort_by/rank/sort_order/asc/cols/stats/asc/cols/stats [Accessed 4 Sep. 2020].

Tomkins, A., Zhang, M. and Heavlin, W.D., 2017. Reviewer bias in single-versus double-blind peer review. Proceedings of the National Academy of Sciences, Vol. 114, No. 48, pp.12708-12713.

United Nations (2019). World Economic Situation and Prospects 2019. [Online]. Available at: https://www.un.org/development/desa/dpad/wp-content/uploads/sites/45/WESP2019_BOOK-web.pdf [Accessed 4 Sep. 2020]. 